$$
\begin{aligned}
& \mathrm{Fe}^{2+}+\mathrm{Dipy} \\
& \stackrel{K_{1}}{\leftrightarrows} \mathrm{Fe}(\mathrm{Dipy})^{2+} \\
& \mathrm{Fe}(\text { Dipy })^{2+}+\text { Dipy } \underset{\boldsymbol{K}_{\mathbf{z}}}{\leftrightarrows} \mathrm{Fe}(\text { Dipy })_{2}{ }^{2+} \\
& \mathrm{Fe}(\text { Dipy })_{2}{ }^{2+}+\text { Dipy } \underset{k j}{\stackrel{k_{b}}{\leftrightarrows}} \mathrm{Fe}(\text { Dipy })_{8}{ }^{2+}
\end{aligned}
$$

where $K_{1}$ and $K_{2}$ are equilibrium constants and $k_{f}$ and $k_{b}$ are forward- and back-rate constants. When the reaction goes to completion, $k_{b}$ can be neglected, and provided the concentrations of $\mathrm{Fe}(\mathrm{Dipy})^{2+}$ and $\mathrm{Fe}$ (Dipy) ${ }_{2}{ }^{2+}$ are small, the above rate equation (1) follows. With this mechanism, $k_{t}$ in equation (1) becomes $K_{1} K_{2} k_{f}$. Evidence that intermediates play a part in the reaction is afforded by our observation that with an excess of $\mathrm{Fe}^{2+}$ over base, the reaction does not go to completion even at $p H \mathbf{H} 6 \cdot 0$, although it does so with equivalent concentrations. For example, with $3 \times 10^{-5} M$ dipyridyl and $6 \times 10^{-4} M$ $\mathrm{Fe}^{2+}$, only 80 per cent of the possible amount of $\mathrm{Fe}(\mathrm{Dipy})_{3}{ }^{2+}$ is formed. Using the above equilibria, it can be shown that, provided $\left[\mathrm{Fe}^{2+}\right]>1 / 2 K_{1}$, an increase in the $\left[\mathrm{Fe}^{2+}\right]$ will decrease the amount of $\mathrm{Fe}$ (Dipy) ${ }_{\mathbf{3}}^{2+}$ formed.

Measurements of $k_{0}$ and $K_{a}$ at different temperatures show that $k_{t}$, that is, $K_{1} K_{2} k_{f}$, is independent of temperature. This indicates that the heats of formation of the intermediate complexes and the activation energy for the formation of $\mathrm{Fe}(\mathrm{Dipy})_{3}{ }^{2+}$ from $\mathrm{Fe}$ (Dipy) ${ }_{2}{ }^{2+}$ are either all zero or cancel out.

In sufficiently acid solution not all the available $\mathrm{Fe}^{2+}$ is converted into the complex, even when dipyridyl is in excess. This is due to the low concentration of free base, and makes possible a determination of the overall equilibrium constant. This has the form :

$$
K=\frac{\left[\mathrm{Fe}(\mathrm{Dipy})_{3}{ }^{2+}\right]}{\left[\mathrm{Fe}^{2+}\right][\mathrm{Dipy}]^{3}} \cdot\left(\frac{K_{a}+\mathrm{H}^{+}}{K_{a}}\right)^{3},
$$

where $K=K_{1} K_{2} k_{f} / k_{b}$. We find $K=4 \times 10^{17} 1 .^{3} \mathrm{~m}^{-3}$ at $17^{\circ} \mathrm{C}$., and $\mu=0.025$.

It was of interest to examine the dissociation of the complex, for we had observed fading of the colour in strong acids. This is presumably the reverse of reaction (iii) brought about by the removal of free base. The reaction is first order, but the constant is dependent on the acid used (hydrochloric, sulphuric or perchloric), and also on its concentration. Thus it increases from $6 \times 10^{-3}$ to $10 \times 10^{-3} \mathrm{~min}^{-1}$ as the acid goes from $0.25 \mathrm{~N}$ to $0.5 \mathrm{~N}$, reaching a steady value of about $12 \times 10^{-3} \mathrm{~min}^{-1}$ for hydro. chloric and sulphuric acids and about $9 \times 10^{-3}$ for perchloric acid, all at $17^{\circ} \mathrm{C}$. This value, combined with $k_{t}$ for the forward reaction, gives a kinetic value of about $9 \times 10^{16}$ for the overall equilibrium constant $K$, and compares as well as can be expected with the direct determination given above. The back reaction is very dependent on temperature, having an activation energy of about $28 \mathrm{k} . c a l$. The dependence on the acid and its concentration, which is at variance with the above scheme, is being examined further. A full account of this work will be published. elsewhere. The investigations are being extended to tripyridyl and tetrapyridyl complexes and their reactions with hydrogen peroxide.

J. H. BAXENDALE Philip George

\section{Chemistry Department,}

University, Leeds.

$$
\text { Aug. } 27 .
$$

${ }^{1}$ Kuhn, R., and Wassermann, A., Annalen, 503, 203 (1933). 2 Lee, T. S., Kolthoff, I. M., and Leussing, D. L., J. Amer. Chem. Soc.,
70, 2348 (1948).

\section{Occurrence of a Phosphate Ester of a Hydroxyamino-Acid}

DURING a recent investigation of the dialysate of calf embryo muscle juice by means of paper chromatography, a very slow-moving spot has been noticed which does not appear to correspond with any substance previously recognized in such extracts. Fractionation of the dialysate on chromatograms of amberlite I.R.4 indicated that it was due to a weakly acidic substance. It was eluted from these chromatograms in the same fraction as phosphoryl aminoethanol, which, contrary to the finding of Outhouse ${ }^{1}$, appears to be present in calf embryos. Thus it seemed worth investigating whether the unknown substance might be another phosphoric ester. This was done as follows.

The fraction from the amberlite column was separated on a one-dimensional paper chromatogram, using phenol/ammonia as solvent. By means of the 'washing off method' of Consden, Gordon and Martin', the substance in question was removed from the paper without treatment with ninhydrin. One sample thus obtained was hydrolysed with $6 \mathrm{~N}$ hydrochloric acid at $100^{\circ}$ for 24 hours and was then again subjected to paper chromatography. Two strong spots were formed, one being due to unchanged material, and the other having $R_{f}$ values in phenol/ammonia and collidine similar to those of hydroxylysine. A second sample was treated at $p \mathrm{H} \mathrm{8-9}$ with the phosphatase from rat intestinal mucosa. After chromatography, the only strong spot formed had the rate expected for hydroxylysine. Certain weak spots which are difficult to identify appeared both here and on the chromatogram of the acid hydrolysate. A third sample was also treated with the phosphatase, but in this case sulphuric acid, sodium molybdate and stannous chloride solutions were added in the proportions given by Kuttner and Lichtenstein ${ }^{3}$. A blue colour was formed. These three experiments indicate that the original substance is a difficultly hydrolysable phosphate ester.

In order to identify further the substance which appeared to be similar to hydroxylysine, an enzyme hydrolysate obtained as above was subjected to chromatography with phenol in an atmosphere containing acetic acid. As expested, the spot obtained had moved very much slower than in phenol/ ammonia. This behaviour is regarded as characteristic of basic substances. Finally, another sample was run as a mixed chromatogram in phenol/ammonia with and without authentic hydroxylysine. The specimen used was obtained from Dr. C. Dent, who received it from Dr. D. D. van Slyke; sincere thanks are due to both. No separation was obtained. Therefore it seems most likely that the original spot must be due to a phosphate ester of hydroxylysine. In view of the possible similarity of this substance with that recently reported by Chargaff ${ }^{4}$ as being present in an acid hydrolysate of ox-brain phosphatides, it seemed worth while to publish these findings at the present stage.

This work was done while I was holding a fellowship from the Donner Foundation, to which thanks are due. A. H. GORDON

Biological Institute of the Carlsberg Foundation, Copenhagen. Sept. 23.

1 Outhouse, E. L., Biochem. J., 31, 1459 (1937).

${ }^{2}$ Consden, R., Gordon, A. H., and Martin, A. J. P., Biochem. J., 41, 590 (1947).

${ }^{3}$ Kuttner, T., and Lichtenstein, L., J. Biol. Chem., 95, 661 (1932).

Chargaff, E., Levine, C., and Green, C., J. Biol. Chem., 175, 67 (1948). 